\title{
Activation of T Lymphocytes in Dengue Virus Infections \\ High Levels of Soluble Interleukin 2 Receptor, Soluble CD4, Soluble CD8, Interleukin 2, and Interferon- $\gamma$ in Sera of Children with Dengue
}

Ichiro Kurane, * Bruce L. Innis, ${ }^{\star}$ Suchitra Nimmannitya," Ananda Nisalak,

Anthony Meager," Jurand Janus," and Francis A. Ennis*

*Division of Infectious Diseases and Immunology, Department of Medicine, University of Massachusetts Medical Center, Worcester, Massachusetts 01655; ${ }^{\ddagger}$ Department of Virology, Armed Forces Research Institute of Medical Sciences, Bangkok, 10400 Thailand; ${ }^{8}$ Children's Hospital, Bangkok, 10400 Thailand; and "Division of Immunobiology, National Institute for Biological Standards and Control, Hertfordshire, EN6 3QG, United Kingdom

\section{Abstract}

It has been reported that the severe complication of dengue virus infection, dengue hemorrhagic fever (DHF) is much more commonly observed during secondary dengue virus infections than primary infections. In order to elucidate the role of $T$ lymphocytes in the pathogenesis of DHF, we attempted to determine whether $T$ lymphocytes are activated in vivo during dengue virus infections, by examining the levels of soluble IL-2 receptor (sIL-2R), soluble CD4 (sCD4), soluble CD8 (sCD8), interleukin-2 (IL-2) and interferon- $\gamma$ (IFNr) in the sera of 59 patients with DHF and 41 patients with dengue fever (DF).

The levels of sIL-2R, sCD4, sCD8, IL-2, and IFN $\gamma$ were significantly higher in the acute sera of patients with DHF than in the sera of healthy children $(P<0.001$ for all markers). The acute sera of patients with DF contained higher levels of SIL$2 \mathrm{R}$, SCD4, IL-2, and IFN $\gamma$ than the sera of healthy children ( $P$ $<0.001$ for sIL-2R, IL-2, and IFN $\gamma ; P<0.05$ for sCD4), but did not have elevated levels of SCD8. The levels of SIL-2R (P $<0.05)$, sCD4 $(P<0.001)$, and SCD8 $(P<0.001)$ were higher in DHF than in DF on days 3-4 after the onset of fever. The levels of IL-2 and IFN $\gamma$ in patients with DHF were highest 1 d before defervescence. There were no significant differences in the levels of sIL-2R, sCD4, sCD8, IL-2, and IFN $\gamma$ among grades 1, 2, and 3 of DHF. These results indicate $(a)$ T lymphocytes are activated and produce IL-2 and IFN $\gamma$ in vivo during DHF and DF, (b) $\mathrm{CD4}^{+} \mathrm{T}$ lymphocytes are activated in DHF and DF, and the level of activation is higher in DHF than in DF, and (c) activation of $\mathrm{CDB}^{+} \mathrm{T}$ lymphocytes is evident in DHF, but not in DF. (J. Clin. Invest. 1991. 88:1473-1480.) Key words: dengue hemorrhagic fever • dengue fever • lymphokines • soluble cell surface proteins $\bullet T$ cell activation

\section{Introduction}

Dengue virus infection presents as two clinical syndromes: dengue fever (DF) ${ }^{1}$ and dengue hemorrhagic fever (DHF) (1).

Address reprint requests to Dr. Francis A. Ennis, Division of Infectious Diseases and Immunology, Department of Medicine, University of Massachusetts Medical Center, Worcester, MA 01655.

Received for publication 31 December 1990 and in revised form 10 June 1991

1. Abbreviations used in this paper: CTL, cytotoxic T lymphocyte; $\mathrm{DF}$, dengue fever; DHF, dengue hemorrhagic fever; DSS, dengue shock syndrome; sCD4, sCD8, or sIL-2R, soluble CD4, CD8, or IL-2 receptor; WHO, World Health Organization.

J. Clin. Invest.

(c) The American Society for Clinical Investigation, Inc.

$0021-9738 / 91 / 11 / 1473 / 08 \$ 2.00$

Volume 88, November 1991, 1473-1480
DF is a self-limited febrile disease and is the most common type of dengue illness. Some patients with dengue virus infection leak plasma into the interstitial space resulting in hypovolemia and sometimes circulatory collapse. This severe syndrome, which is always accompanied by thrombocytopenia and sometimes by frank hemorrhage, is termed DHF (1). The World Health Organization (WHO) categorized DHF cases into four grades, from less severe (grade 1) to sever (grade 4) (2). Grades 3 and 4, in which plasma leakage is so profound that shock occurs, are also referred to as dengue shock syndrome (DSS) (2). Epidemiological studies in Southeast Asia indicate that DHF is more commonly observed during secondary infections with a different serotype of virus from that which caused the primary infection $(1,3,4)$. A much higher incidence of DHF during secondary infections was also observed in a recent dengue epidemic in Cuba (5). DHF occurs rarely during primary infections, but it has been observed in infants from 6 to 12 mo of age born to dengue antibody-positive mothers (6). It is known that antibody to dengue viruses at subneutralizing concentrations augments dengue virus infection of $\mathrm{Fc} \gamma$ receptor $(\mathrm{Fc} \gamma \mathrm{R})$-positive cells such as monocytes in vitro (7), and it has been reported that passively transferred antibody enhances dengue virus infection in monkeys (8). Based on these epidemiological and laboratory observations, it has been hypothesized that antibody to dengue virus increases the number of dengue virusinfected monocytes and lysis of these virus-infected cells may lead to $\operatorname{DHF}(1,9)$.

We have studied $T$ lymphocyte responses to dengue viruses to determine their role in the pathogenesis of DHF and in recovery from dengue virus infections. Dengue virus-specific, serotype-cross-reactive $\mathrm{CD}^{+}{ }^{+} \mathrm{T}$ lymphocytes produce interferon- $\gamma$ (IFN $\gamma$ ) after stimulation with dengue virus antigen (10). IFN $\gamma$, which increases the number of $F c \gamma R$, augments dengue virus infection of $\mathrm{Fc} \gamma \mathrm{R}$-positive cells in the presence of antibody to dengue virus (11). Furthermore, dengue virus-specific $\mathrm{CD}^{+}$ $\mathrm{CD8}^{-} \mathrm{T}$ lymphocytes and $\mathrm{CD}^{-} \mathrm{CD8}^{+} \mathrm{T}$ lymphocytes lyse dengue virus-infected target cells in a human histocompatibility leukocyte antigen (HLA) class II- and HLA class I-restricted fashion, respectively $(12,13)$. Based on these in vitro results, we have hypothesized that dengue virus-specific, serotype-cross-reactive $T$ lymphocytes, which are activated during secondary dengue virus infection, may contribute to the pathogenesis of DHF by producing IFN $\gamma$ and by lysing dengue virus-infected monocytes (14). It has also been reported that monocytes are among the most permissive cells for dengue virus replication (15-17) and that lymphokines produced by $T$ lymphocytes activate monocytes (18).

Activated T lymphocytes secrete interleukin 2 (IL-2) (18$20)$, and $\operatorname{IFN} \gamma(18,20)$, and release soluble interleukin 2 receptor (sIL-2R) (21), soluble CD8 $(\operatorname{sCD} 8)(22,23)$, and soluble 
CD4 (sCD4) (Susan Kline, personal communication). In this paper, we analyze the activation of $\mathrm{T}$ lymphocytes in vivo by measurements of sIL-2R, sCD4, sCD8, IL-2, and IFN $\gamma$ in the sera of Thai children with DHF or DF. The results show that sera from patients with DHF and from those with DF contain higher levels of sIL-2R, sCD4, sCD8, IL-2, and IFN $\gamma$ than the sera from healthy Thai children except for SCD8 in DF, and suggest that $\mathrm{T}$ lymphocytes are activated during dengue virus infections. The levels of sIL-2R, sCD4, and sCD8 are significantly higher in patients with DHF than in patients with uncomplicated DF. These results indicate that $\mathrm{CD}^{+} \mathrm{T}$ lymphocytes are activated in DHF and DF, and that activation of $\mathrm{CD}^{+} \mathrm{T}$ cells is evident in DHF, but not in DF. This is the first demonstration of the activation of $\mathrm{T}$ lymphocytes in vivo in dengue virus-infected patients, and the results suggest that the marked activation of $\mathrm{T}$ cells may contribute to the severe complication of dengue virus infections.

\section{Methods}

Patients and normal control donors. Sera from three groups of children were analyzed in this study. We examined serial serum specimens from 69 children (59 with DHF and 10 with DF), ages 4-14 yr, who were hospitalized with severe dengue virus infections during 1987 and 1988 in the hemorrhagic fever unit of the Bangkok Children's Hospital. These represent an unselected group of sequential patients whose sera were submitted for evaluation of suspected dengue infection. Specimens were collected by study nurses for diagnostic studies within $24 \mathrm{~h}$ of admission to the hospital and daily until discharge; a convalescent specimen was also collected from each child 7-15 d after hospital admission. A portion of each specimen was kept at $-70^{\circ} \mathrm{C}$ and was available for analysis.

To study children with less symptomatic dengue infection, we also examined prospectively collected 14-d paired sera from 57 children, ages 6-14 yr, who were absent from school for $>2 \mathrm{~d}$ with a febrile illness during the period June to September 1989. These children were participating in an approved prospective study of the incidence of viral hepatitis in rural Thailand. Sera from this group of children were divided into specimens from children with documented dengue infections $(n=31)$ and from children with uncharacterized, non-flavivirus infections $(n=26)$. Acute sera were collected within $3 \mathrm{~d}$ of a child's confinement at home with fever; specimens were frozen at $-70^{\circ} \mathrm{C}$ until analyzed. Convalescent sera were also collected and they were stored at $-20^{\circ} \mathrm{C}$. To study afebrile children (controls), we examined aliquots of single sera from a random sample of healthy Thai children $(n=97)$, ages 6-13 yr, obtained from an earlier approved cross-sectional study of hepatitis antibody prevalence. These sera were stored at $-70^{\circ} \mathrm{C}$ from the time of collection until assay. Levels of cytokines were examined after the first thaw, and levels of soluble cell surface proteins were examined after the second thaw, because soluble cell surface proteins are less susceptible to freezing and thawing than cytokines. Because the volumes of the sera obtained from patients were limited, all the sera could not be examined for every cytokine or soluble cell surface protein.

Diagnoses of DHF were assigned to children with dengue infection when the level of thrombocytopenia and signs of hemorrhage and plasma leakage met established criteria (2). Hospitalized patients were followed with frequent determinations of blood pressure and pulse. Measurements of hematocrit in blood obtained by finger prick were recorded at 1-8-h intervals, according to vital signs. Physical findings of plasma leakage (pleural effusion, ascites, cyanosis, cold extremities) were recorded in the clinical record. Whenever feasible, chest radiographs including decubitus views were performed to document the presence of pleural fluid. Hemorrhagic manifestations (positive tourniquet test for capillary fragility, skin hemorrhages, epistaxis, gingival, gastrointestinal, or urinary tract hemorrhage) were also recorded. Upon hospital discharge, the WHO grade of dengue illness was determined by a review of the clinical record. Without knowledge of cytokine or soluble lymphocyte marker levels, the authors (Drs. Nisalak, Innis, and Nimmannitya) reviewed every record including radiographs and confirmed the assignment of WHO grade. All mildly symptomatic serologically confirmed dengue infections in outpatients were classified as dengue fever. Hospitalized cases of dengue infection that did not meet diagnostic criteria for DHF were classified as DF $(n=10)$ along with mildly symptomatic outpatients.

Dengue virus and Japanese encephalitis virus infections were confirmed by detection of antiviral IgM or rising titers of antiviral hemagglutination-inhibiting antibodies and by virus isolation from plasma, according to previously published methods (24). No patient in the Children's Hospital group had a serological diagnosis of Japanese encephalitis. Two patients in the outpatient group had a serological diagnosis of Japanese encephalitis virus infection. These two patients were excluded from this study. Cases of dengue infection were categorized as secondary (dengue infection in a child previously infected with a heterologous flavivirus) or primary (no prior flavivirus infection) according to the presence or absence of an anamnestic anti-flavivirus antibody response (24). Table I shows age and sex distribution, and serological data of the donors.

Assays for $s I L-2 R, s C D 4$, and $s C D 8$. The levels of sIL-2R, sCD4, and SCD8 were measured using commercial enzyme-linked immunosorbent assays (ELISA) (cell-free interleukin-2 receptor test kit, cellfree CD4 test kit, and cell-free T8 test kit, respectively) purchased from T Cell Sciences, Inc., Cambridge, MA. The results are expressed in units per milliliter based on the standard provided by the manufacturer.

Table I. Age and Sex Distribution and Serological Data of the Donors

\begin{tabular}{|c|c|c|c|c|c|c|}
\hline \multirow[b]{2}{*}{ Donor } & \multirow[b]{2}{*}{ Number } & \multicolumn{2}{|c|}{ Sex } & \multirow{2}{*}{$\begin{array}{l}\text { Average age } \pm \text { SD } \\
\text { (Range) }\end{array}$} & \multicolumn{2}{|c|}{ Dengue serology } \\
\hline & & Male & Female & & Primary & Secondary \\
\hline & & & & $y r$ & & \\
\hline DHF & 59 & 28 & 31 & $\begin{array}{c}8.9 \pm 3.0 \\
(4-14)\end{array}$ & 7 & 52 \\
\hline DF & 41 & 22 & 19 & $\begin{array}{c}9.8 \pm 2.1 \\
(5-14)\end{array}$ & 6 & 35 \\
\hline Uncharacterized & & & & & & \\
\hline febrile diseases & 26 & 12 & 14 & $\begin{array}{c}9.5 \pm 1.6 \\
(6-14)\end{array}$ & 0 & 0 \\
\hline Healthy children & 97 & 45 & 52 & $\begin{array}{c}7.9 \pm 1.6 \\
(6-13)\end{array}$ & 0 & 0 \\
\hline
\end{tabular}




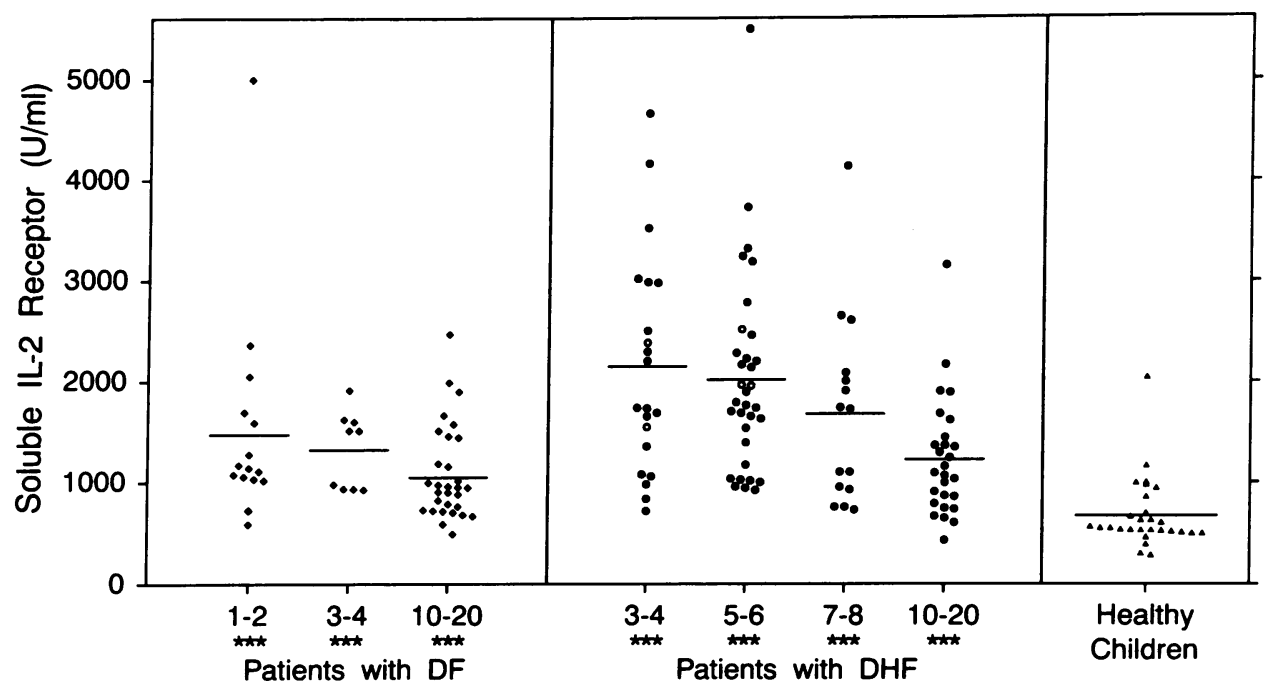

Days After Onset of Fever
Figure 1. Levels of sIL-2R in the acute sera of patients with DF or DHF. The arithmetic mean titers (shown as $\longrightarrow$ ) of sIL-2R were 665 $\mathrm{U} / \mathrm{ml}(n=28)$ in the sera of healthy Thai children; $1,475 \mathrm{U} / \mathrm{ml}(n=16)$ on days $1-2,1,325 \mathrm{U} / \mathrm{ml}(n=9)$ on days $3-4$, and $1,050 \mathrm{U} / \mathrm{ml}(n=32)$ on days 10-20 in the sera of patients with DF; $2,150 \mathrm{U} / \mathrm{ml}(n=21)$ on days $3-4,2,019 \mathrm{U} / \mathrm{ml}(n=33)$ on days $5-6,1,681 \mathrm{U} / \mathrm{ml}(n=16)$ on days $7-8$, and $1,225 \mathrm{U} / \mathrm{ml}(n=27)$ on days 10-20 in the sera of patients with DHF. In DHF and DF, (O) primary, hospitalized; (๑) secondary, hospitalized; $(\diamond)$ primary, not hospitalized; ( $\bullet$ ) secondary, not hospitalized. Levels of sIL-2R were compared with the levels in the healthy children by Student's $t$ test. ${ }^{* * *} P$ $<0.001$.
Assays for IL-2. The levels of IL-2 were measured using commercial ELISA (Intertest-2) purchased from Genzyme, Boston, MA. The levels of IL-2 are expressed in units per milliliter.

Assay for IFN . Levels of IFN $\gamma$ were measured using a commercial radioimmunoassay (RIA) (Centocor gamma interferon radioimmunoassay) purchased from Centocor Diagnostics, Malvern, PA. The results are expressed in international units per milliliter.

Statistical analysis. Differences between values were examined by Student's $t$ test and $\chi^{2}$ square test. Correlations of values were examined by Pearson correlation coefficients (25). When the titers of lymphokines and soluble cell surface proteins differed $>10$-fold in a group of sera, the titers were log-transformed. Therefore, titers of IL-2 and IFN $\gamma$ were log-transformed for statistical analysis. Undetectable levels of IL-2 $(<4 \mathrm{U} / \mathrm{ml})$ and IFN $\gamma(<0.07 \mathrm{U} / \mathrm{ml})$ were considered 1 and $0.05 \mathrm{U} / \mathrm{ml}$ for log-transformation, respectively. When data of one subject were available on each adjacent day for analyses shown in Figs. 1-5 and Table II (e.g., days 3 and 4 after onset of fever), the arithmetic mean titers were used for sIL-2, sCD4, and sCD8; and the geometric mean titers were used for IL- 2 and IFN $\gamma$. Differences yielding $P$ values of $\leq 0.05$ were regarded as significant.

\section{Results}

Levels of $s I L-2 R, s C D 4$, and sCD8 in patients with DHF or DF. The sera from patients with DHF or DF were examined for the levels of sIL-2R, sCD4, and sCD8, and the levels were compared with those in the sera of healthy Thai children.

The levels of sIL-2R were significantly higher in the sera of patients with DHF and in the sera of patients with DF than in the sera of healthy Thai children during the examined period $(P$ $<0.001$ for DHF, $P<0.001$ for DF) (Fig. 1).

The levels of SCD4 were higher in the sera of patients with DHF on days 3-8 after onset of fever $(P<0.001)$ than in the healthy children. The levels of SCD4 in the sera of patients with DF were higher than the levels in healthy children on days 1-2 after onset of fever $(P<0.05)$, but not on days 3-4 (Fig. 2).

The levels of SCD8 were higher in the sera of patients with DHF on days 3-20 after onset of fever than in the sera of healthy children $(P<0.001)$. The levels of SCD8 in the sera of

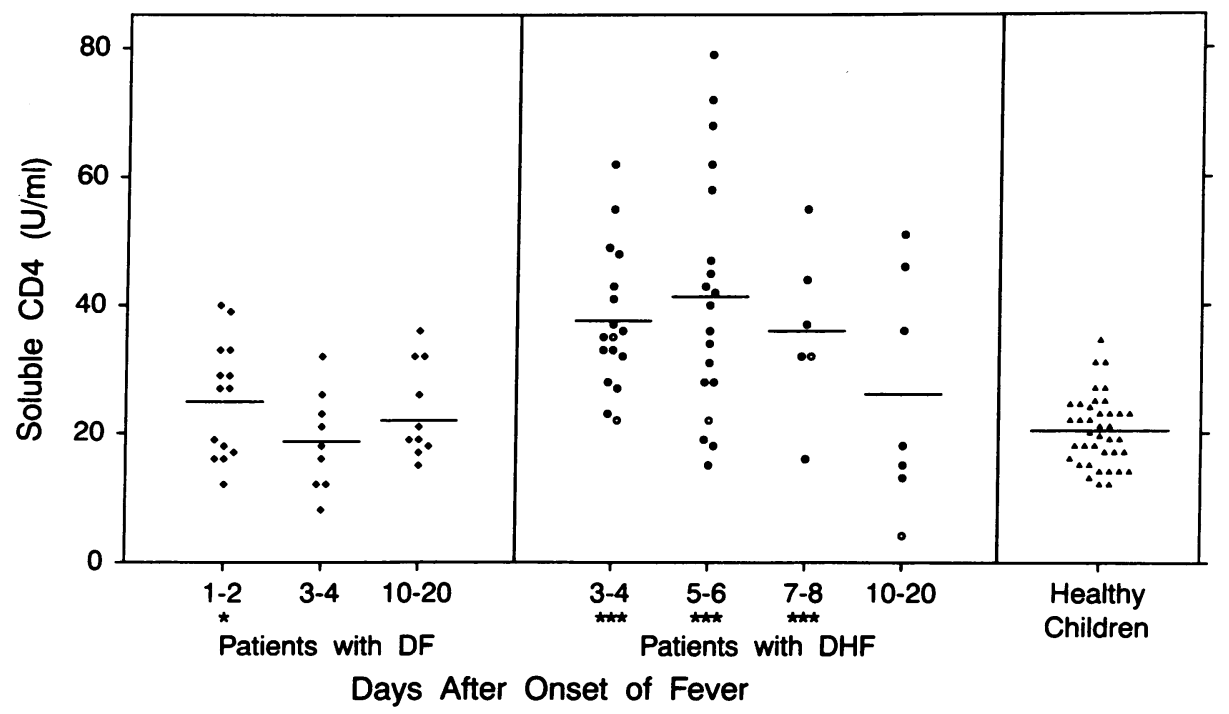

Figure 2. Levels of soluble CD4 (sCD4) in the acute sera of patients with DF or DHF. The arithmetic mean titers (shown as -) of sCD4 were $20.4 \mathrm{U} /$ $\mathrm{ml}(n=40)$ in the sera of healthy Thai children; $24.9(n=15)$ on days $1-2$, $18.7 \mathrm{U} / \mathrm{ml}(n=9)$ on days $3-4$, and 22.0 $(n=11)$ on days $10-20$ in the sera of patients with DF; $37.6 \mathrm{U} / \mathrm{ml}(n=17)$ on days $3-4,41.4 \mathrm{U} / \mathrm{ml}(n=19)$ on days $5-6,36.0 \mathrm{U} / \mathrm{ml}(n=6)$ on days $7-8$, and $26.1 \mathrm{U} / \mathrm{ml}(n=7)$ on days 10-20 in the sera of patients with DHF. In DHF and DF, (O) primary, hospitalized; $(\bullet)$ secondary, hospitalized; $(\diamond)$ primary, not hospitalized; ( $\bullet$ secondary, not hospitalized. Levels of SCD4 were compared with the levels in the healthy children by Student's $t$ test. ${ }^{*} P$ $<0.05,{ }^{* * *} P<0.001$. 


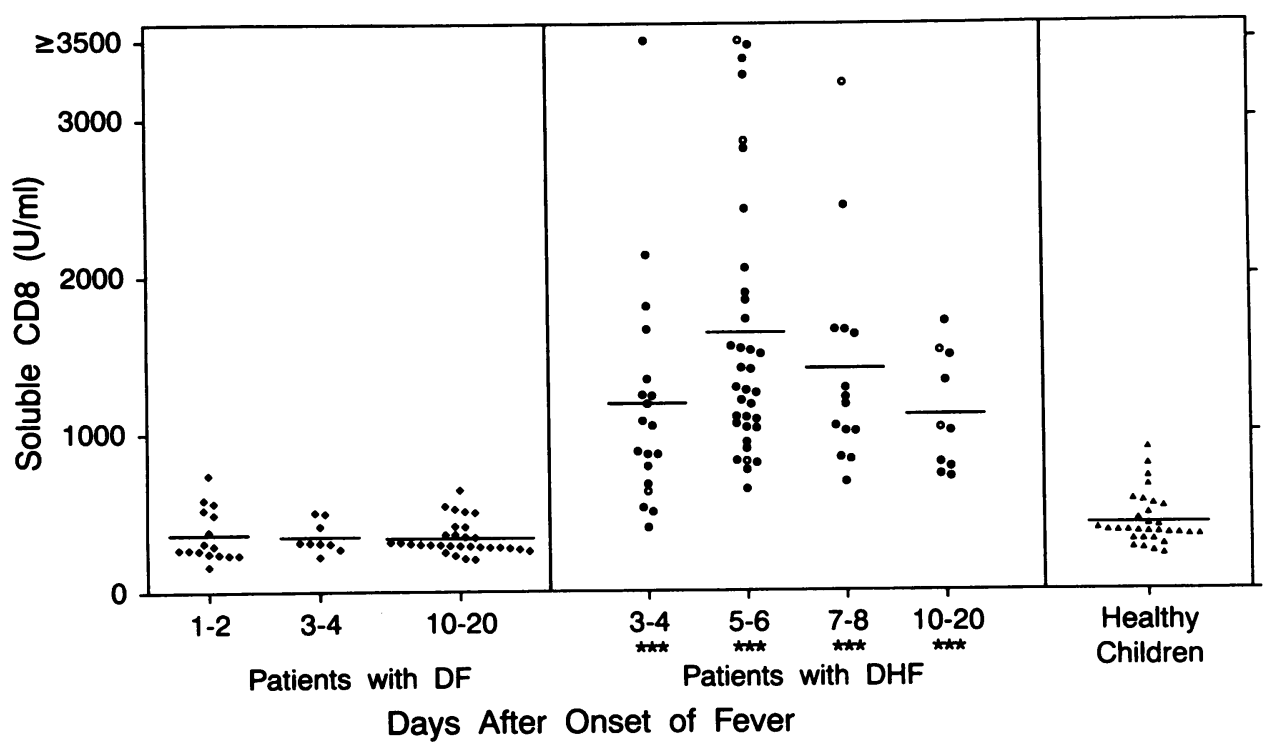

Figure 3. Levels of SCD8 in the acute sera of patients with (DF) or DHF. The arithmetic mean titers (shown as - of sCD8 were 416 $\mathrm{U} / \mathrm{ml}(n=31)$ in the sera of healthy Thai children; $359 \mathrm{U} / \mathrm{ml}(n=16)$ on days $1-2,344 \mathrm{U} / \mathrm{ml}(n=9)$ on days $3-4,334 \mathrm{U} / \mathrm{ml}(n=30)$ on days $10-20$ in the sera of patients with DF; $1,188 \mathrm{U} / \mathrm{ml}(n=19)$ on days $3-4,1,639 \mathrm{U} / \mathrm{ml}(n=35)$ on days $5-6,1,410 \mathrm{U} / \mathrm{ml}(n=14)$ on days $7-8$ and $1,112 \mathrm{U} / \mathrm{ml}(n=10)$ on days $10-20$ in the sera of patients with DHF. In DHF and DF, (O) primary, hospitalized; (•) secondary, hospitalized; $(\diamond)$ primary, not hospitalized; (४) secondary, not hospitalized. Levels of SCD8 were compared with the levels in healthy Thai children by Student's $t$ test. ${ }^{* * *} P$ $<0.001$. patients with DF were not elevated during days 1-20 (Fig. 3). These results suggest that $\mathrm{CD} 4^{+} \mathrm{T}$ lymphocytes are activated in vivo during $\mathrm{DHF}$ and $\mathrm{DF}$, and that activation of $\mathrm{CD8}^{+}$lymphocytes is evident in DHF, but not in DF.

Levels of IL-2 and IFN $\gamma$ in the sera of patients with DHF or $D F$. The sera from patients with DHF or DF were examined for IL-2 or IFN. IL-2 levels $>10 \mathrm{U} / \mathrm{ml}$ were detected in $63 \%$ (26/ 41) of patients with DHF during days 3-8 after onset of fever, and in $69 \%(18 / 26)$ of patients with DF during days $1-4$, whereas only 2 of 28 sera of healthy children contained IL-2 $>10 \mathrm{U} / \mathrm{ml}\left(P<0.001\right.$ for DHF, $P<0.001$ for DF by $\chi^{2}$ square test) (Fig. 4). The titers of IL-2 were significantly higher in the sera of patients with DHF $(P<0.001$ on days $3-8,10-20)$ and in the sera of patients with DF $(P<0.001$ on days $1-2$ and $10-20$, and $P<0.01$ on days $3-4$ ) than in the sera of healthy Thai children (Fig. 4).

IFN $\gamma$ was detected in $97 \%(34 / 35)$ of the patients with DHF, and in $91 \%(31 / 34)$ of patients with DF, while it was detected in $13 \%(4 / 30)$ of the sera of healthy children $(P$ $<0.001$ for DHF, $P<0.001$ for DF by $\chi^{2}$ test) (Fig. 5). The titers of IFN $\gamma$ in the sera of patients with DHF on days 3-8 $(P$ $<0.001$ on days 3-6 and $P<0.02$ on days 7-8) and in the sera of patients with DF on days $1-4(P<0.001)$ were significantly higher than those in the sera of healthy children (Fig. 5).

These results are consistent with those in Figs. 1-3, and indicate that $T$ lymphocytes are activated in vivo during DHF and DF.

Comparison of the levels of soluble cell surface proteins and lymphokines between DHF and DF. A comparison of SIL-2R, sCD4, sCD8, IL-2, and IFN $\gamma$ among patients with DHF or DF were made for sera collected on illness days 3-4, because specimens were obtained from patients with DHF during days 3-8 after onset of fever and from patients with DF during days 1-4. The sera of patients with DHF contained higher levels of sIL$2 \mathrm{R}(P<0.05)$, sCD4 $(P<0.001)$, and SCD8 $(P<0.001)$ than the sera of patients with DF, although the levels of IL-2 and

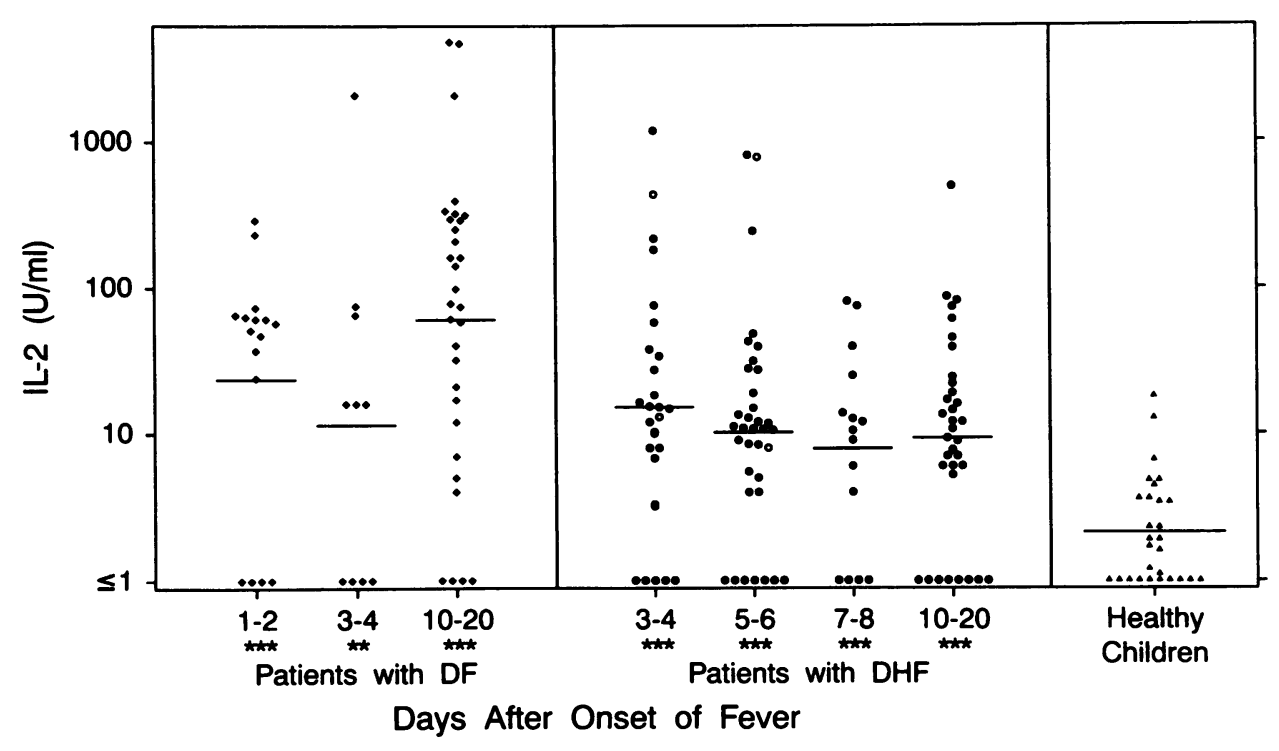

Figure 4. Levels of IL-2 in the acute sera of patients with DF or DHF. The geometric mean titers (shown as $\longrightarrow$ ) of IL-2 were $2.1 \mathrm{U} / \mathrm{ml}(n$ $=28)$ in the sera of healthy Thai children; $23.6 \mathrm{U} / \mathrm{ml}(n=16)$ on days $1-2,11.5 \mathrm{U} / \mathrm{ml}(n=10)$ on days $3-4,60.3 \mathrm{U} / \mathrm{ml}(n=31)$ on days $10-20$ in the sera of patients with DF; $15.2 \mathrm{U} / \mathrm{ml}(n=27)$ on days $3-4,10.2 \mathrm{U} / \mathrm{ml}(n=36)$ on days $5-6,7.9 \mathrm{U} / \mathrm{ml}(n=15)$ on days $7-8$, and $9.3 \mathrm{U} / \mathrm{ml}(n=34)$ on days 10-20 in the sera of patients with DHF. In DHF and DF, (O) primary, hospitalized; (๑) secondary, hospitalized; $(\diamond)$ primary, not hospitalized; ( $\bullet$ secondary, not hospitalized. Levels of IL-2 were compared with the levels in healthy Thai children by Student's $t$ test after log-transformation. ${ }^{* *} P<0.01,{ }^{* * *} P<0.001$. 


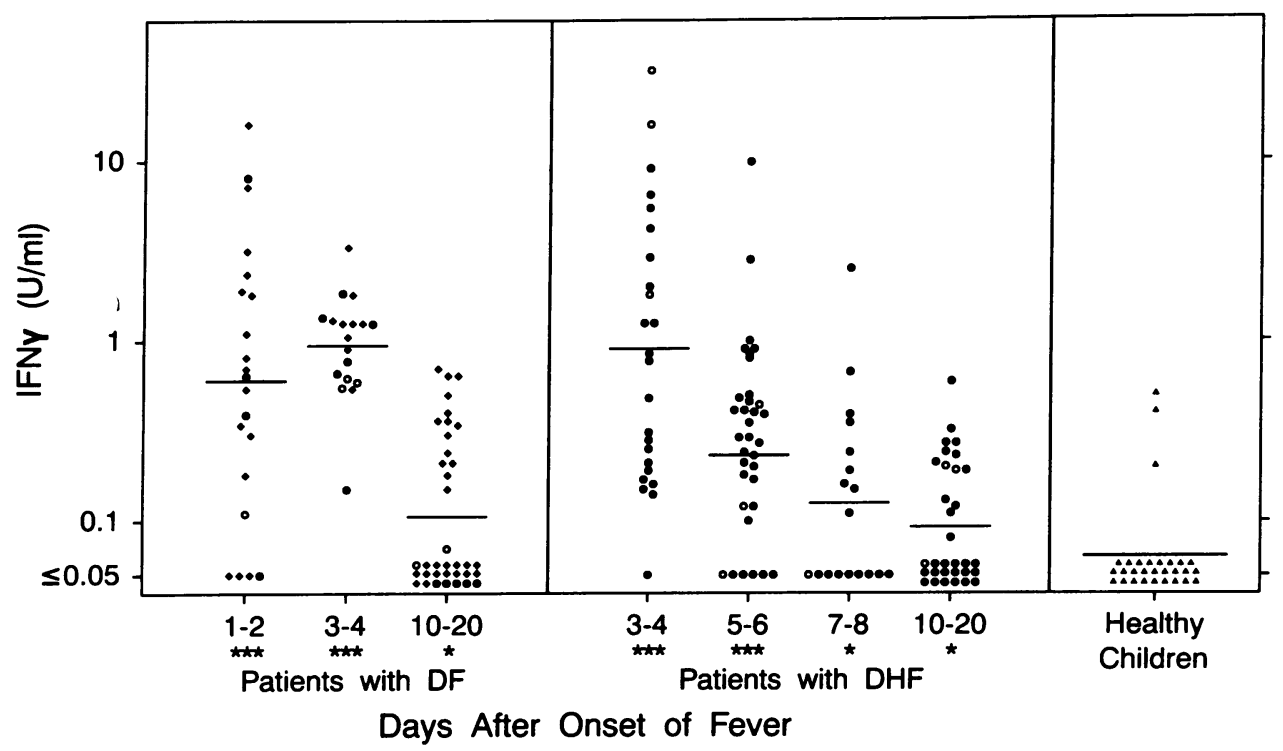

Figure 5. Levels of IFN $\gamma$ in the acute sera of patients with DHF and with DF. The geometric mean titers (shown as -) of IFN $\gamma$ were 0.064 $\mathrm{U} / \mathrm{ml}(n=30)$ in the sera of healthy Thai children, $0.604 \mathrm{U} / \mathrm{ml}(n=21)$ on days $1-2,0.945 \mathrm{U} / \mathrm{ml}(n=18)$ on days $3-4$, and $0.106 \mathrm{U} / \mathrm{ml}(n=$ 36) in the sera of patients with DF, and $0.904 \mathrm{U} / \mathrm{ml}(n=28)$ on days $3-4,0.231 \mathrm{U} / \mathrm{ml}(n=34)$ on days $5-6,0.125 \mathrm{U} / \mathrm{ml}(n=18)$ on days $7-8$, and $0.029 \mathrm{U} / \mathrm{ml}(n=32)$ on days $10-20$ in the sera of patients with DHF. In DHF/DSS and DF, (O) primary, hospitalized; (•) secondary, hospitalized; $(\diamond)$ primary, not hospitalized; $(\bullet)$ secondary, not hospitalized. Levels of IFN $\gamma$ were compared with the levels in the healthy Thai children by Student's $t$ test after $\log$-transformation. ${ }^{*} P$ $<0.05,{ }^{* * *} P<0.001$.
IFN $\gamma$ were not different between DHF and DF (Table II). These results suggest that activation of $T$ lymphocytes is greater in DHF than in DF. The levels of sIL-2R, IL-2, and IFN $\gamma$ were elevated in the sera of patients with unidentified febrile diseases on days $1-2$, and the levels are similar to those in the sera of patients with DF (data not presented).

Levels of $s I L-2 R, s C D 4, s C D 8, I L-2$, and IFN $\mathrm{r}$ in patients with $D H F$ before and after the day of defervescence. The timing of plasma leakage in patients with DHF is quite predetectable; circulatory collapse occurs or peaks as fever subsides. Therefore, we examined the change in the levels of soluble cell surface proteins and lymphokines in patients with DHF around the day of defervescence termed day 0 in this analysis. Mean levels of sIL-2R, SCD4, and sCD8 were similar during day -1 to day 1 (Fig. 6). The titers of IL-2 and IFN $\gamma$ were highest one day before defervescence (Fig. 7). These results suggest that activation of $\mathrm{T}$ lymphocytes reaches the peak as plasma leakage begins but before circulatory collapse becomes manifest.

Comparison of the levels of each serum factor among the WHO grades 1, 2, and 3 of DHF. The levels of soluble cell surface proteins and lymphokines were compared among grades 1,2 , and 3 of DHF from day -1 to day 3 . Statistically significant differences were observed only in the levels of sCD4 between grade 1 and grade 3 one day after defervescence (Fig. 8 ) and in the levels of IL-2 between grade 2 and grade $31 \mathrm{~d}$ before defervescence (Fig. 9). As a whole, the levels of sIL-2R, sCD4, sCD8, IL-2, and IFN $\gamma$ were not different among grades 1,2 , and 3 of DHF. These results suggest that the degree of $T$ cell activation is similar among grades 1,2 , and 3 of DHF, and that our grouping all grades of DHF for analysis was appropriate.

Correlation between the levels of SIL-2R and those of SCD4 in patients with $D H F$. We examined whether there were correlations between the levels of sIL-2R, sCD4, sCD8, IL-2, and IFN $\gamma$ in the acute sera of patients with DHF. The levels of sIL-2R positively correlated with those of SCD4 $(P=0.025)$ (Fig. 10). There were no other correlations among the levels of lymphokines and soluble cell surface proteins.

\section{Discussion}

We examined levels of lymphokines (IL-2 and IFN $\gamma$ ) and soluble cell surface proteins (sIL-2, sCD4, and SCD8) released from activated $\mathrm{T}$ lymphocytes in unselected Thai children hospitalized with DHF. To determine whether differential cytokines or

Table II. Levels of Soluble Cell Surface Proteins and Lymphokines in DHF and DF on Days 3-4 after the Onset of Fever*

\begin{tabular}{|c|c|c|c|c|c|}
\hline \multirow[b]{2}{*}{ Markers } & \multicolumn{2}{|c|}{ DHF } & \multicolumn{2}{|c|}{ DF } & \multirow[b]{2}{*}{$P$ value } \\
\hline & Titers & (No. of samples) & Titers & (No. of samples) & \\
\hline & $U / m l$ & (n) & $U / m l$ & (n) & \\
\hline SIL-2R & $2,232 \pm 218$ & (23) & $1,325 \pm 127$ & (9) & $<0.05$ \\
\hline SCD4 & $37.6 \pm 2.7$ & (17) & $18.7 \pm 2.7$ & (9) & $<0.001$ \\
\hline SCD8 & $1,188 \pm 176$ & (19) & $344 \pm 33$ & (9) & $<0.001$ \\
\hline IL-2 $\left(\log _{10}\right)$ & $1.181 \pm 0.156$ & (27) & $1.062 \pm 0.348$ & (10) & NS \\
\hline IFN $\gamma\left(\log _{10}\right)$ & $-0.044 \pm 0.153$ & (24) & $-0.024 \pm 0.068$ & (18) & NS \\
\hline
\end{tabular}

* Levels of sIL-2R, sCD4, sCD8, IL-2, and IFN $\gamma$ on days 3-4 after the onset of fever were compared between DHF and DF by Student's $t$ test. The titers of IL-2 and IFN $\gamma$ were log-transformed for analysis. The numbers in the parentheses depict the number of samples. NS denotes statistically not significant. 


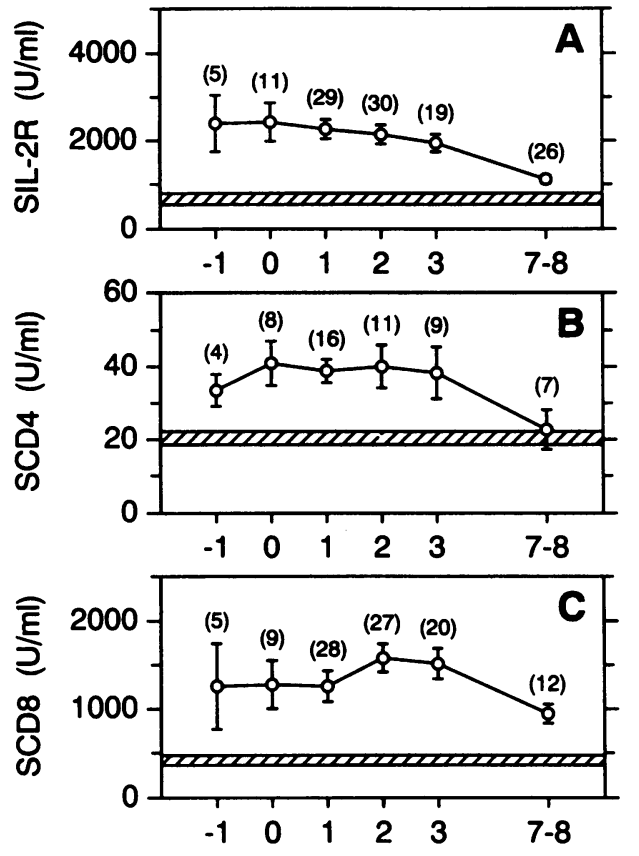

Days Before or After Defervescence

Figure 6. Levels of sIL-2R, sCD4, and sCD8 in patients with DHF before and after the day of defervescence. Numbers in the parentheses depict the number of samples. Levels are shown as mean \pm standard error or mean (SEM). ( $₫$ ) Mean titers $\pm 1.96 \times$ SEM in the sera of healthy Thai children.

cellular immune responses were associated with hemorrhage and plasma leakage that are the pathognomonic feature of DHF, we also examined these same serum factors in patients who were infected with dengue virus but who did not have plasma leakage (dengue fever). Children with DF were drawn from the same consecutive hospital case series as those with DHF, or they were drawn from a consecutive series of DF cases
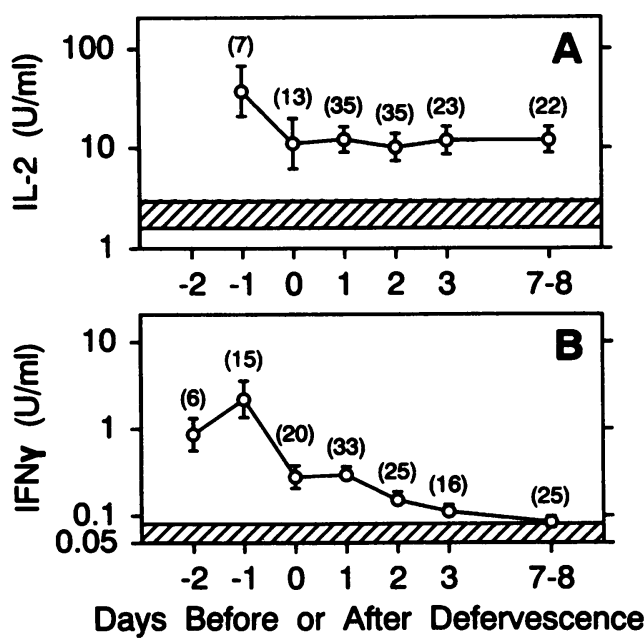

Figure 7. Levels of IL-2 and IFN $\gamma$ in patients with DHF before and after the day of defervescence. Numbers in the parentheses depict the number of samples. Levels are shown as mean titers \pm standard error of mean (SEM). ( $₫)$ mean titer $\pm 1.96 \times$ SEM in the sera of healthy Thai children.
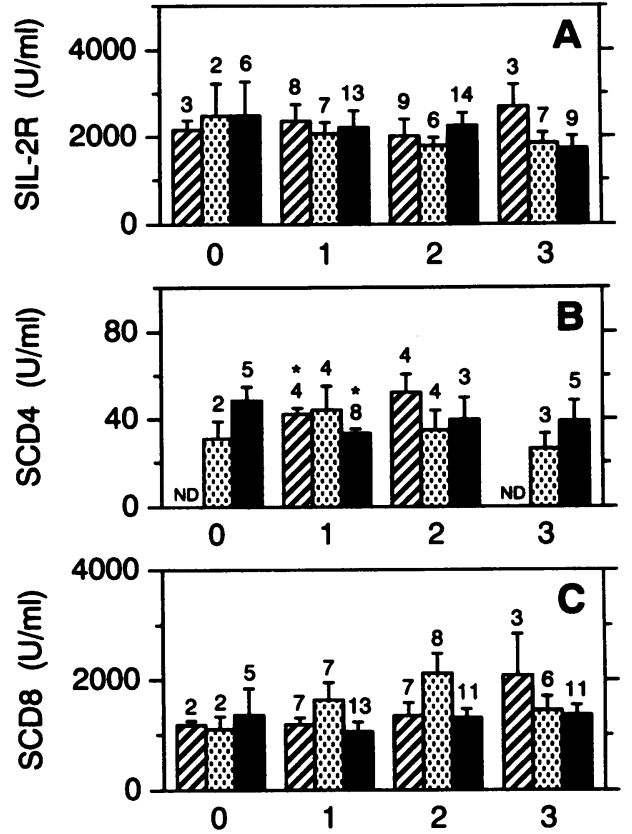

Days Before or After Defervescence

Figure 8. Levels of sIL-2R, sCD4, and SCD8 in grades 1, 2, and 3 of DHF. Levels are shown as mean titers + SEM. Numbers above the bars depict the number of samples. ${ }^{*} P<0.05$ compared by Student's $t$ test. (回) Grade 1; (田) grade 2; ( $\square$ ) grade 3.

identified prospectively during a longitudinal study of illnesses leading to school absence in rural Thailand. To determine which findings in the entire set of patients with dengue virus infection were indicative of a host response to viral infection, we examined sera collected from healthy Thai children from the same cohort which yielded the dengue fever cases. We found evidence of marked $T$ cell activation in patients with
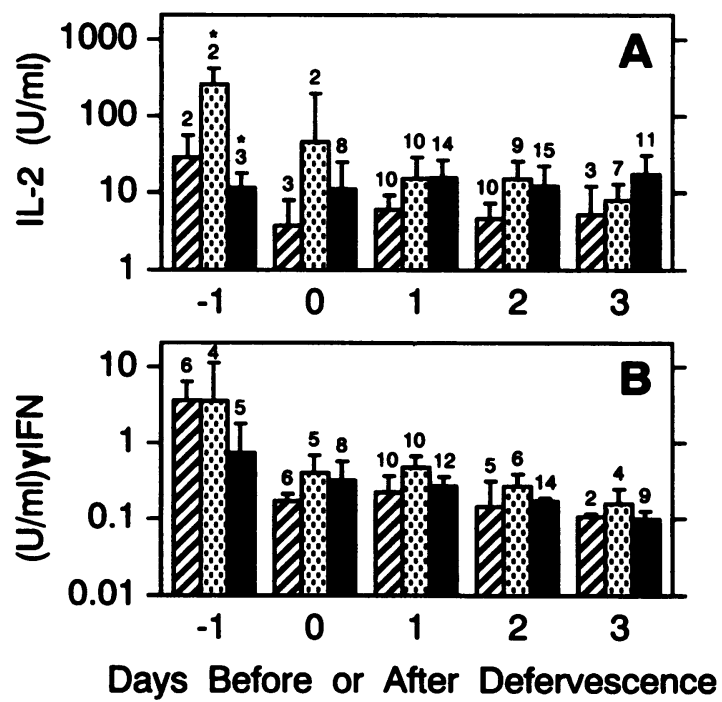

Figure 9. Levels of IL-2 and IFN $\gamma$ in grades 1, 2, and 3 of DHF. Levels are shown as mean titers + SEM. Numbers above the bars depict the number of samples. ${ }^{*} P<0.05$ compared by Student's $t$ test. (घ) Grade 1; (घ) grade 2; (ø) grade 3. 


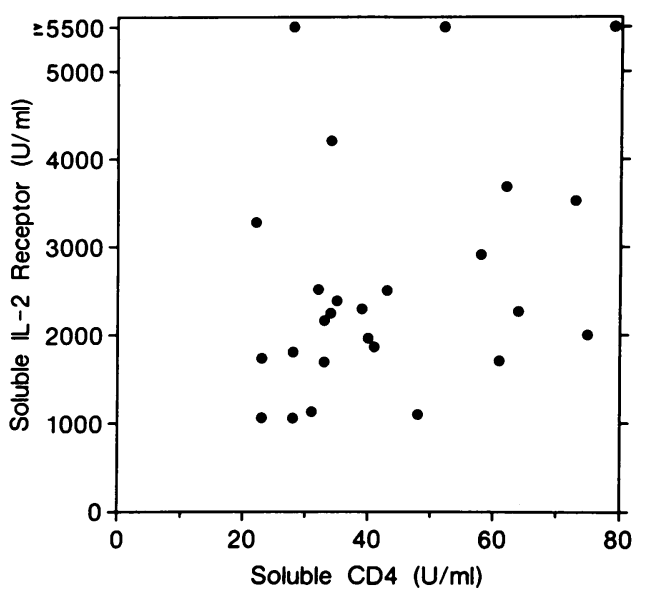

Figure 10. Correlation between the levels of sIL-2R and SCD4 in the acute sera of patients with DHF. The highest titers of sIL-2R and sCD4 in the sera of each patient during days 3-8 were used for calculation of Pearson correlation coefficient $(0.3893, n=26, P=0.025)$.

DHF. T cell activation in patients with DF was similar to that seen in other acute febrile diseases, and was not as profound as in patients with DHF.

Among patients with DHF, levels of sIL-2R, sCD4, sCD8, IL-2, and IFN $\gamma$ were higher than those in the sera of healthy Thai children. It is known from in vitro studies that activated $T$ lymphocytes produce IL-2 $(18-20)$ and $\operatorname{IFN} \gamma(18,20)$, and release sIL-2R (21). Activated $\mathrm{CD}^{+} \mathrm{T}$ lymphocyte release sCD8 $(22,23)$, while activated $\mathrm{CD}^{+} \mathrm{T}$ lymphocytes release sCD4 (Susan Kline, personal communication). We previously reported that dengue virus-specific $\mathrm{CD}^{+} \mathrm{CD} 8^{-}$memory $\mathrm{T}$ cells are induced by dengue virus infections (10). They produce IFN $\gamma(10,12)$ and IL-2 (unpublished data) after stimulation with dengue virus antigens in vitro. We have also detected $\mathrm{CD}^{+} \mathrm{CD}^{-}$cytotoxic $\mathrm{T}$ lymphocytes (CTL) using lymphocytes of dengue virus-immune donors (13). The high levels of sIL-2R, sCD4, sCD8, IL-2, and IFN $\gamma$ reported in this paper suggest that $\mathrm{CD}^{+} \mathrm{CD}^{-}$and $\mathrm{CD} 4^{-} \mathrm{CD}^{+} \mathrm{T}$ cells observed in vitro are activated in vivo in the acute phase of DHF. Mean levels of sIL-2R, sCD4, sCD8, IL-2, and IFN $\gamma$ were similarly high among WHO grades 1, 2, and 3 of DHF, and differences in the severity of DHF were not reflected in the apparent degree of $T$ cell activation. However, the absence of difference in the levels of serum factors among WHO grades 1, 2, and 3 of DHF may be partially due to small sample numbers. $T$ cell activation may be different between patients with primary and secondary dengue virus infections manifesting DHF. However, in this study there were only seven patients with primary DHF, and differences were not detected. Dengue virus serotype might also influence the degree of $T$ cell activation. However, dengue virus were isolated from only 9 out of 59 patients with DHF: dengue- 1 virus from two patients, dengue- 2 virus from three patients, and dengue- 3 virus from four patients. These numbers were too small to determine whether there is any difference in $\mathrm{T}$ cell activation among the dengue virus serotypes.

Among patients with DF, the acute sera contained higher levels of sIL-2R, sCD4, IL-2, and IFN $\gamma$ than the sera of healthy children. SCD8 levels were not elevated in most cases; however, high levels of $\mathrm{sCD} 8$ were detected in the small number of hospitalized patients with DF on days 5-8 after onset of fever when sera were available (data not presented). Sera of patients with DHF contained higher levels of sIL-2R, sCD4, and sCD8 than the sera of patients with DF. These results indicate that the levels of activation of $\mathrm{CD}^{+}$and $\mathrm{CD}^{+} \mathrm{T}$ lymphocytes are higher in DHF than in DF, and suggest that high levels of T cell activation may be associated with the pathogenesis of DHF. However, the possibility that the higher levels of soluble factors in DHF reflect a high level of inflammatory responsiveness rather than actually causing hemorrhage and plasma leakage cannot be ruled out.

Elevated levels of sIL-2R have been reported in measles (26), HTLV-1 (27), and HIV infections (28-30). Elevated levels of SCD8 have been reported in measles (26) and EpsteinBarr virus infections (23). Elevated levels of IFN $\gamma$ have been reported in measles (31). We also observed elevated levels of sIL-2R, IL-2, and IFN $\gamma$ in the sera of Thai children with uncharacterized febrile diseases other than DF, DHF, and Japanese encephalitis (data not presented). These results suggest that $\mathrm{T}$ lymphocytes are activated during systemic virus infections, and that elevation of serum levels of sIL-2R, sCD4, sCD8, IL-2, and IFN $\gamma$ is not unique to dengue virus infections.

The role of lymphokines in the pathogenesis of DHF is an interesting subject to be studied. IL-2 induces plasma leakage in humans when administered at doses $>10^{5} \mathrm{U} / \mathrm{kg}(32,33)$. Although the mechanism of the IL-2-induced plasma leakage is not clearly understood, IL-2 is known to induce lymphokineactivated killer (LAK) cells (34) and thromboxane $A_{2}$ (35), and activate endothelial cells (36), any of which may conceivably alter endothelial permeability to cause plasma leakage. Activation of the complement system, which is observed in DHF (1), has been observed in patients administered high doses of IL-2, and the levels of plasma C3a correlated with signs of vascular leak syndrome (37). These observations suggest that the high levels of IL-2 detected in the sera of patients with DHF may be one factor which contribute to plasma leakage and shock in DSS. However, we detected similar levels of IL-2 in the sera of patients with DF, therefore, it is unlikely that IL-2 alone induces DHF.

We have hypothesized that IFN $\gamma$ produced by dengue specific $T$ cells may contribute to the pathogenesis of DHF (14). It is known that IFN $\gamma$ increases the number of Fc $\gamma \mathrm{RI}$ on monocytic cells $(38,39)$. We have reported that IFN $\gamma$ augments dengue virus infection of human monocytic cells in the presence of antibody to dengue viruses (11). IFN $\gamma$ also up-regulates expression of HLA class I and class II antigens (40). These effects of IFN $\gamma$ may increase the number of dengue virus-infected monocytes and facilitate recognition of dengue virus antigen by dengue virus-specific $\mathrm{T}$ cells. The lysis of dengue virus-infected monocytes by these CTL may release vasoactive mediators which contribute to DHF. The elevated levels of IFN $\gamma$ in the sera of most of the dengue patients suggest that these mechanisms may occur in vivo. However, we detected similar levels of IFN $\gamma$ in DHF and DF; therefore, IFN $\gamma$ alone is probably not responsible for the pathogenesis of DHF. It is possible that cytokines released from monocytes may contribute to the pathogenesis of DHF. We did not detect TNF $\alpha$ in the sera of 18 patients with DHF between days 1 and 11 (data not presented). However, it is interesting to examine serum levels of other monokines in patients with DHF or DF.

We observed significant correlations between the severity of illness (DHF vs. DF) and elevated levels of sIL-2R, sCD4, and SCD8, but not with elevated levels of lymphokines. Plasma 
leakage during dengue virus infections may not be the result of any single lymphokine. Marked activation of T cells does however appear to be a feature of such cases. Therefore, future examination of the interaction of immune effector cells and infected target cells will be important to elucidate the pathogenesis of plasma leakage. Despite our failure to detect a correlation between serum levels of lymphokines and plasma leakage, we want to emphasize that the patients we investigated were admitted to the hospital when symptoms were already severe or rapidly worsening. It is possible that many of the host immune responses had been already activated and some of the secreted lymphokines had been eliminated or degraded before sera were obtained. It would be desirable to serially evaluate a cohort of patients beginning earlier in the course of dengue virus infection to determine whether elevated serum levels of specific lymphokines predict the appearance of plasma leakage.

\section{Acknowledgments}

We thank Dr. Robert Lew for statistical analysis.

This work was supported by grants from the U. S. Army Medical Research and Development Command (DAMA 17-86-C-6208), and from the National Institutes of Health (NIH-RO1 AI30624, NIH-T32A 107272). The opinions contained herein are those of the authors and should not be construed as representing the official policies of the Department of Army or the Department of Defense.

\section{References}

1. Halstead, S. B. 1980. Immunological parameters of togavirus disease syndromes. In The Togaviruses: Biology, Structure, Replication. R. W. Schlesinger, editor. Academic Press, Inc., New York. 107-173.

2. Technical Advisory Committee on Dengue Hemorrhagic Fever for Southeast Asian and Western Pacific Regions. 1980. Guide for Diagnosis, Treatment, and Control of Dengue Hemorrhagic Fever. World Health Organization, Geneva, Switzerland.

3. Halstead, S. B. 1981. The pathogenesis of dengue: molecular epidemiology in infectious disease. Am. J. Epidemiol. 114:632-648.

4. Burke, D. S., A. Nisalak, D. Johnson, and R. M. Scott. 1988. A prospective study of dengue infections in Bangkok. Am. J. Trop. Med. Hyg. 38:172-180.

5. Kouri, G., M. G. Guzman, and J. Bravo. 1986. Hemorrhagic dengue in Cuba: history of an epidemic. Pan Am. Health Organ. Bull. 20:24-30.

6. Halstead, S. B. 1988. Pathogenesis of dengue: Challenges to molecular biology. Science (Wash. DC). 239:476-481.

7. Halstead, S. B. and E. J. O'Rourke. 1977. Dengue virus and mononuclear phagocytes. I. Infection enhancement by non-neutralizing antibody. J. Exp. Med. 146:201-217.

8. Halstead, S. B. 1979. In vivo enhancement of dengue virus infection in rhesus monkeys by passively transferred antibody. J. Infect. Dis. 140:527-533.

9. Halstead, S. B. 1981. Dengue hemorrhagic fever-a public health problem and a field for research. Bull. WHO. 58:1-21.

10. Kurane, I., B. L. Innis, A. Nisalak, C. Hoke, S. Nimmanitya, A. Meager, and F. A. Ennis. 1989. Human T cell responses to dengue virus antigens: proliferative responses and interferon gamma production. J. Clin. Invest. 83:506-513.

11. Kontny, U., I. Kurane, and F. A. Ennis. 1988. Gamma interferon augments $\mathrm{Fc}-\gamma$ receptor-mediated dengue virus infection of human monocytic cells. J. Virol. 62:3928-3933.

12. Kurane, I., A. Meager, and F. A. Ennis. 1989. Dengue virus-specific human $T$ cell clones: serotype cross-reactive proliferation, interferon gamma production, and cytotoxic activity. J. Exp. Med. 170:763-775.

13. Bukowski, J. F., I. Kurane, C.-J. Lai, M. Bray, B. Falgout, and F. A. Ennis. 1989. Dengue virus-specific cross-reactive $\mathrm{CD}^{+}$human cytotoxic T lymphocytes. J. Virol. 63:2486-2491.

14. Kurane, I. U. Kontny, A. L. Rothman, and F. A. Ennis. 1989. Interferon$\gamma$ production by dengue antigen-specific $\mathrm{T}$ lymphocytes: possible immunopathological role in secondary dengue virus infections. In Vaccines 89: Modern Approaches to New Vaccines Including Prevention of AIDS. R. A. Lerner, R. Ginsberg, R. M. Chanock, and E. Brown, editors. Cold Spring Harbor Laboratory, New York. 367-370.

15. Halstead, S. B., E. J. O'Rourke, and A. C. Allison. 1977. Dengue virus and mononuclear phagocytes. II. Identity of blood and tissue leukocytes supporting in vitro infection. J. Exp. Med. 146:218-229.
16. Boonpucknavig, V., N. Bhamarapravati, S. Boonpucknavig, P. Futrakul, and P. Tanpaichitr. 1976. Glomerular changes in dengue hemorrhagic fever. Arch. Pathol. Lab. Med. 100:206-212.

17. Boonpuchnavig, S., V. Boonpuchnavig, S. Bhamarapravati, and S. Nimmannitya. 1979. Immunofluorescence study of skin rash in patients with dengue hemorrhagic fever. Arch. Pathol. Lab. Med. 103:463-466.

18. Balkwill, F. R., and F. Burke. 1989. The cytokine network. Immunol. Today. 10:299-304.

19. Smith, K. A. 1980. T cell growth factor. Immunol. Rev. 31:337-352.

20. Granelli-Piperno, A., L. Andrus, and R. M. Steinman. 1986. Lymphokine and nonlymphokine mRNA levels in stimulated human T cells. J. Exp. Med. 163:922-937.

21. Rubin, L. A., C. C. Kurman, M. E. Fritz, W. E. Biddison, B. Boutin, B. Yarchoan, and D. L. Nelson. 1985. Soluble interleukin 2 receptors are released from activated human lymphoid cells in vitro. J. Immunol. 135:3172-3177.

22. Fujimoto, J., S. Levy, and R. Levy. 1983. Spontaneous release of the Leu-2 (T8) molecule from human T cells. J. Exp. Med. 159:752-766.

23. Tomkinson, B. E., M. C. Brown, S. H. Ip, S. Carrabis, and J. L. Sullivan. 1989. Soluble CD8 during T cell activation. J. Immunol. 142:2230-2236.

24. Innis, B. L., A. Nisalak, S. Nimmannitya, S. Kusalerdchariya, V. Chongswasdi, S. Suntayakorn, P. Puttisri, and C. H. Hoke. 1989. An enzyme-linked immunoadsorbent assay to characterize dengue infections where dengue and Japanese encephalitis co-circulate. Am. J. Trop. Med. Hyg. 40:418-427.

25. Downie, N. M. and R. W. Heath. 1970. Testing the significance of correlation coefficients. In Basic Statistical Methods. N. M. Downie and R. W. Heath, editors. Harper \& Row Publishers, New York. 230-240.

26. Griffin, D. E., B. J. Ward, E. Jauregui, R. T. Johnson, and A. Vaisberg. 1989. Immune activation in measles. $N$. Engl. J. Med. 320:1667-1672.

27. Yamaguchi, K., Y. Nishimura, T. Kiyokawa, and K. Takatsuki. 1989. Elevated serum levels of soluble interleukin-2 receptors in HTLV-1-associated myopathy. J. Lab. Clin. Med. 114:407-410.

28. Prince, H. E., S. Kleinman, and A. E. Williams. 1988. Soluble IL-2 receptor levels in serum from blood donors seropositive for HIV. J. Immunol. 140:1139-1141.

29. Lang, J. M., G. Coumaros, S. Levy, A. Falkenrodt, M. Steckmeyer, M. Partisani, A. Aleksijevic, L. Lehr, and C. Koehl. 1988. Elevated serum levels of soluble interleukin 2 receptors in HIV infection: correlation studies with markers of cell activation. Immunol. Lett. 19:99-102.

30. Honda, M., K. Kitamura, K. Matsuda, Y. Yokota, N. Yamamoto, R. Mitsuyasu, J.-C. Chermann, and T. Tokunaga. 1989. Soluble IL-2 receptors in AIDS. Correlation of its serum level with the classification of HIV-induced diseases and its characterization. J. Immunol. 142:4248-4255.

31. Griffin, D. E., B. J. Ward, E. Jauregui, R. T. Johnson, and A. Vaisberg. 1990. Immune activation during measles: interferon- $\gamma$ and neopterin in plasma and cerebrospinal fluid in complicated and uncomplicated disease. J. Infect. Dis. 161:449-453.

32. Rosenberg, S. A., M. T. Lotze, L. M. Muul, S. Leitman, A. E. Chang, S. E. Ettinhausen, Y. L. Matory, J. M. Skibber, E. Shiloni, J. T. Vetto, et al. 1985. Observations on the systemic administration of autologous lymphokine-activated killer cells and recombinant interleukin-2 to patients with metastatic cancer. N. Engl. J. Med. 313:1485-1492.

33. Lotze, M. T., Y. L. Matory, S. E. Ertinghausen, A. A. Rayner, S. O. Sharrow, C. A. Y. Seipp, M. C. Custer, and S. A. Rosenberg. 1985. In vivo administration of purified human interleukin 2. II. Half life, immunologic effects, and expansion of peripheral lymphoid cells in vivo with recombinant IL2. $J$. Immunol. 135:2865-2875.

34. Peace, D. J., and M. A. Cheever. 1989. Toxicity and therapeutic efficacy of high-dose interleukin 2. In vivo infusion of antibody to NK-1.1 attenuates toxicity without compromising efficacy against murine leukemia. J. Exp. Med. 169:161-173.

35. Ferro, J. T., A. Johnson, J. Everitt, and A. B. Malik. 1989. IL-2 induces pulmonary edema and vasoconstriction independent of circulating lymphocytes. J. Immunol. 142:1916-1921.

36. Cotran, R. S., J. S. Pober, A. Gimbrone, Jr., T. A. Springer, E. A. Wiebke, A. A. Gaspari, S. A. Rosenberg, and M. T. Lotze. 1987. Endothelial activation during interleukin-2 immunotherapy: A possible mechanism for the vascular leak syndrome. J. Immunol. 139:1883-1888.

37. Thijs, L. G., C. E. Hack, R. J. M. S. Van Schijndel, J. H. Nuijens, G. Jan Wolbin, A. J. M. Erenberg-Belmer, H. Van der Vall, and J. Wagstaff. 1990. Activation of the complement system during immunotherapy with recombinant IL-2: Relation to the development of side effects. J. Immunol. 144:2419-2424.

38. Guyre, P. M., P. Morganerli, and R. Miller. 1983. Recombinant immune interferon increases immunoglobulin G Fc receptors on cultured human mononuclear phagocytes. J. Clin. Invest. 72:393-397.

39. Perussia, B., E. T. Dayton, R. Lazarus, V. Fanning and G. Trinchieri. 1983. Immune interferon induces the receptor for monomeric IgG1 on human monocytic and myeloid cells. J. Exp. Med. 158:1092-1113.

40. Kelley, V. E., W. Fiers, and T. B. Strom. 1983. Cloned human interferon$\gamma$, but not interferon- $\beta$ or $-\alpha$, induces expression of HLA-DR determinants by fetal monocytes and myeloid leukemic cell lines. J. Immunol. 132:240-245. 